\title{
Screening for Multiple Autoantibodies in Plasma of Patients with Breast Cancer
}

\author{
LAUREN BASSARO ${ }^{1}$, STEPHEN J. RUSSELL ${ }^{1}$, ELZBIETA PASTWA ${ }^{1}$, \\ STELLA A. SOMIARI ${ }^{2}$ and RICHARD I. SOMIARI ${ }^{1}$ \\ ${ }^{1}$ Functional Genomics \& Proteomics Unit, ITSI-Biosciences, Johnstown, PA, U.S.A.; \\ ${ }^{2}$ Biobanking \& Biospecimen Science Research Unit, Windber Research Institute, Windber, PA, U.S.A.
}

\begin{abstract}
Background/Aim: Autoantibodies have potential as circulating biomarkers for early cancer detection. This study aimed to screen for known autoantibodies in human plasma using an Autoantibody Profiling System (APS) and quantify the levels in plasma of donors with/without breast cancer. Materials and Methods: Plasma from nine female donors diagnosed with breast cancer (test group) and nine matched donors with no personal history of cancer (reference group) were screened with an APS containing probes for 30 autoantibodies. Autoantibody levels $\geq 1.5$ times the mean concentration of the group were considered elevated, and test/reference ratios $\geq 1.3$ were considered higher in the test group compared to the reference group. Results: Twenty percent of the probes detected elevated levels of autoantibodies against proteins involved in different cancer mechanisms. Amongst these, the levels of autoantibodies against interleukin 29 (IL29), osteoprotegerin $(O P G)$, survivin (SUR), growth hormone $(G R H)$ and resistin (RES) were significantly higher in the cancer group compared to the reference group $(p<0.05)$, whereas the level of autoantibody against cytotoxic T-lymphocyte associated antigen-4 (CTLA4) was not significantly different between the two groups $(p=0.38)$. Conclusion: Disease-relevant autoantibodies were detected in the plasma of patients with breast cancer and donors without breast cancer. This means that identifying the type and level of autoantibodies in samples will be important in determining their significance in the disease process. A microtiter plate-based array system
\end{abstract}

This article is freely accessible online.

Correspondence to: Richard I. Somiari, Ph.D., Functional Genomics \& Proteomics Unit, ITSI-Biosciences, 633 Napoleon Street, Johnstown, PA 15901, U.S.A. E-mail: Richard@itsi.us

Key Words: Antigen array, autoantibody detection, breast cancer, plasma screening. could be a fast and inexpensive screening method for identifying and quantifying autoantibodies in human plasma.

Cancer still imposes a significant public health burden around the world. It is the second leading cause of death in the USA, and the American Cancer Society projects that over 600,000 Americans will die from cancer in 2017 (1). Leukemia, brain cancer, and breast cancer in females are amongst the leading causes of cancer-related deaths among individuals before the age of 40 years, and lung cancer is the leading cause of cancer-related death among individuals aged 40 years and older. The most common causes of cancer deaths among men are cancer of the colon, lung, and prostate, whereas colon, lung, and breast cancer are the most common causes of cancer deaths in women. Cancer of the colon, lung, prostate, and breast alone account for $46 \%$ of all deaths due to cancer in the USA (1).

Our group has been interested in breast cancer for over 15 years. This type of cancer, which affects both men and women, still attracts significant interest because it is the second leading cause of cancer death in women in the USA. It is the most common form of cancer among women with an estimated 252,710 new cases predicted to occur in 2017, representing $15 \%$ of all new cancer cases in the USA. Additionally, it is estimated that 40,610 deaths due to breast cancer will occur in 2017 (2). Breast cancer has a high mortality rate due to rapid cancer cell proliferation and a great degree of malignancy. One of the key issues in breast cancer diagnosis is that traditional diagnostic methods, such as mammography and other methods of breast examination, are not adequately sensitive for early tumor detection $(3,4)$. Because of this, there is a need for new methods of detection, including identification of biomarkers which could offer more effective and minimally invasive diagnostic techniques.

Current progress in detection and characterization of tumor-associated antigens implies that the corresponding autoantibodies can be diagnostic biomarkers. Autoantibodies 
are a class of antibodies that are produced against a body's own proteins. These biomarkers have noteworthy advantages compared to other types of biomarkers, particularly, the ability to be detected prior to clinical manifestations of a disease and their stability and accessibility in blood $(5,6)$. For example, autoantibodies are found at high levels in serum in spite of low levels of their corresponding antigen (6), and they persist for an extensive amount of time even after the antigen is no longer detectable (7). Because of this, a simple-to-use microtiter plate-based autoantibody profiling system can be used to detect and quantify disease-associated autoantibodies in human plasma (8).

Autoantibody generation can be influenced by a range of factors, some of which include pathogens via epitope mimicking, chemicals, genetic predisposition, and the environment (9-11). Within the past 30 years, various studies have been dedicated to explaining the production, progression and functions of autoantibodies and the autoantigens they target. Accumulating scientific evidence suggests the critical roles autoantibodies possess in homeostasis, that is, maintenance of health via autoclearance of aged cells, as well as auto-clearance of dysfunctional dividing cells in patients with cancer $(10,12)$. This class of candidate protein biomarkers has become of interest in cancer detection because autoantibodies can easily be detected in patient blood by means of minimally invasive blood collection techniques (11) and some of them have been shown to be at increased levels in early-stage cancer (11-16). Autoantibodies are produced early in tumorigenesis and have demonstrated the possibility of being detected from several months or years before clinical symptoms develop (17-19).

An Autoantibody Profiling System-90 (APS-90; ITSI Biosciences, Johnstown, PA, USA) has been used to screen human plasma to identify and quantify disease-associated autoantibodies (8). The APS kit includes a 96-well microtiter plate containing 90 antigens against proteins relevant in autoimmune and complex diseases such as cancer. The array contains four standards used for the generation of a standard curve, positive and negative controls, and all the relevant reagents in a ready-to-use format (8). Based on results obtained after screening plasma samples from donors diagnosed with ovarian cancer, a miniAPS array was developed that consists of 30 antigens, some of which were found to be elevated in patients with ovarian cancer (8).

The aim of this study was to screen for known autoantibodies in the plasma of patients diagnosed with breast cancer, and to determine if the detected autoantibodies are also present in donors without breast cancer. This article describes a fast and easy method for detecting elevated autoantibodies in plasma and discusses the significance of the elevated autoantibodies detected in breast cancer.

\section{Materials and Methods}

Sample population. The plasma samples used for this study were obtained from the Windber Tissue Repository of the Windber Research Institute, Windber, PA, USA. All samples were from fully informed and consenting female donors who were 21 years of age or older at the time the samples were collected. The donor samples which were randomly selected from the Windber Tissue Repository were stratified into the following two categories: a) Nine individuals with no personal history of cancer, the reference group; and b) nine individuals with a clinical diagnosis of either ductal carcinoma in situ or infiltrating ductal carcinoma, the test group. The test group samples were obtained pre-operatively from women undergoing surgery for suspected breast cancer whose surgical pathology eventually confirmed ductal carcinoma in situ or infiltrating ductal carcinoma. All samples were collected between 2003 and 2005 using a Windber Research Institute Institutional Review Board approved protocol (protocol \#: Pro 00009470) and stored at $-190^{\circ} \mathrm{C}$ until used for this study. The total protein content of each sample was quantified using the ToPA Bradford protein assay kit (ITSI-Biosciences) as previously described, to ensure that an equal amount of total protein was used in the assay (8).

Detection of autoantibodies in plasma. Plasma samples were pooled in sets of three within each study group. This consisted of $300 \mu \mathrm{l}$ per sample for a total volume of $900 \mu \mathrm{l}$ per pool. Plasma samples were screened with a mini-APS array (ITSI-Biosciences, Johnstown, PA, USA) using the protocol previously described (8). The miniAPS kit contained a microtiter plate containing 30 antigens, arrayed in triplicate, and ready-to-use reagents. Briefly, nine samples from individuals diagnosed with breast cancer were pooled into sets of three (Figure 1). Each set was diluted 1:10 with working buffer, and used as the test samples (T1, T2, and T3). Nine samples from individuals with no diagnosis or history of breast cancer were also pooled into sets of three, and each set was diluted 1:10 with working buffer, and used as the reference samples (R1, R2, and R3). A total of six mini-APS plates were used to independently screen the plasma samples. To screen for the targeted autoantibodies, $50 \mu \mathrm{l}$ of pooled, undiluted plasma was added to each well in the microtiter plate and the plate was incubated for 2 $\mathrm{h}$ at room temperature. After incubation, the supernatant was removed by aspiration with a pipette and discarded. The plates were washed 3 times with $300 \mu l$ of wash buffer and the detection antibody (50 $\mu 1,1: 10,000$ dilution) was added to each well. The plates were incubated at room temperature for $1 \mathrm{~h}$ and washed four times with $300 \mu$ l of wash buffer. Fifty microliters of the colorimetric reagent was then added to each well and the plates were incubated at room temperature in the dark. After $30 \mathrm{~min}, 25$ $\mu \mathrm{l}$ of the 'Stop' solution was added to quench the reaction. The plates were shaken on a plate shaker for $30 \mathrm{~s}$ and the absorbance (optical density; OD) was then measured at $405 \mathrm{~nm}$ with an ELx $800^{\mathrm{TM}}$ microplate reader (BioTek, Winooski, VT, USA). All OD readings were completed within 30 min of stopping the reaction.

Data analysis. The absorbance from each microplate reading was transferred to Microsoft Excel and the concentrations of autoantibodies $(\mu \mathrm{g} / \mathrm{ml})$ calculated using the generated standard curve. In this study, we empirically determined the limit of detection (LoD) to be equal to an optical density of $2.831(\mathrm{LoD}=45.608 \mu \mathrm{g} / \mathrm{ml})$, and 


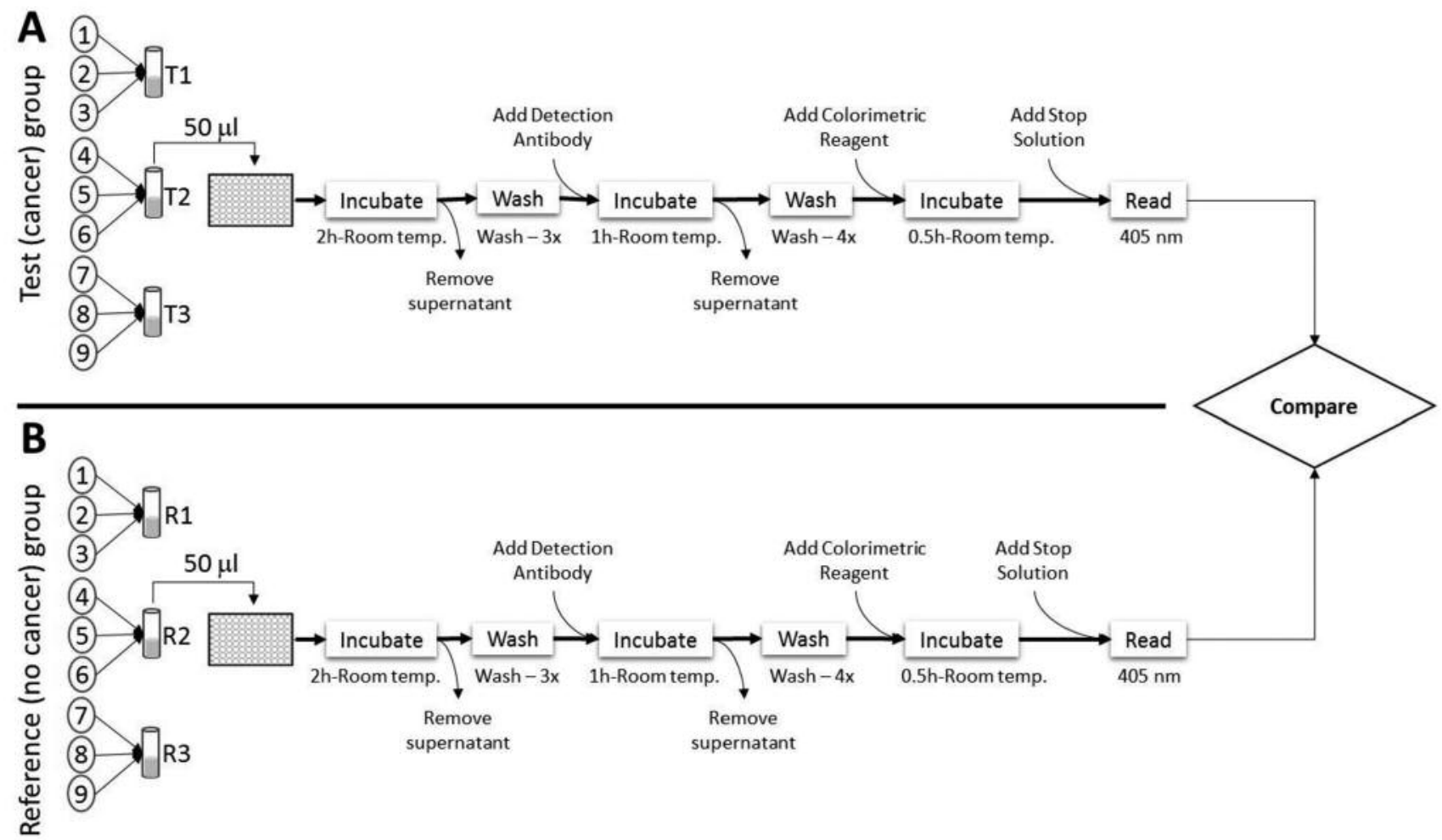

Figure 1. Schematic illustration of the Autoantibody Profiling System workflow for screening of plasma. A: Plasma from nine donors diagnosed with breast cancer was used as the test group. Three samples were pooled to obtain three test samples (T1, T2, and T3). B: Plasma from nine donors with no history of breast cancer was used as the reference $(R)$ group. Three samples were pooled to obtain three reference samples $(R 1, R 2$, and R3). Only the screening of sample T2 and R2 are illustrated. A total $50 \mu l$ of each pooled sample was used for the assay. A total of six mini-APS plates were used for the study. All incubations and washes were performed at ambient temperature and the assay lasted for about $4 \mathrm{~h}$.

the limit of quantitation (LoQ) to be less than or equal to an optical density of 8.579 (LoQ $\leq 60.490 \mu \mathrm{g} / \mathrm{ml})$. Additional analysis of the output data was conducted using the Four Parametric Logistic Regression data analysis tool for determination of the autoantibody concentration when the OD was outside the standard curve range (20). Autoantibodies that occurred at elevated levels in the test and reference groups were identified as previously reported with some modification (8). Briefly, a cut-off value was established by multiplying the mean OD obtained for each group by a factor of 1.5. Thus, if the OD $450 \mathrm{~nm}$ for an autoantibody was $\geq 1.5$ of the mean of the group, the autoantibody was classified as being elevated in that sample and if $<1.5$ of the mean OD of the group, that autoantibody was classified as not being elevated in that sample. For statistical confidence, the Student's t-test was performed to estimate the statistical significance of the difference in autoantibody levels between the test and reference groups. The cut-off used for statistical significance was $p<0.05$.

To determine the relative abundance of each autoantibody in the test and reference samples, the mean concentration of each autoantibody classified as being elevated in a test sample was divided by the mean concentration of the same autoantibody classified as being elevated in a reference sample to obtain a test/reference $(T / R)$ ratio. Elevated autoantibodies with a T/R ratio $\geq 1.3$ were classified as higher in the test group, whereas $T / R$ ratios $\leq 0.7$ were classified as lower in the test group. The $T / R$ ratios of $\geq 0.8$ and $\leq 1.2$ were classified as having similar levels in the test and reference groups.

\section{Results}

Detection of autoantibodies in human plasma. The primary objective of the study was to screen for known autoantibodies in plasma of patients with breast cancer. The secondary objective was to determine if the autoantibodies detected in these patients were also present in matched donors with no personal history of breast cancer. The mini-APS kit used contained 30 autoantibody probes that were chosen based on the results of our previous study using plasma obtained from donors with ovarian cancer (8). To control for sample variability, three samples within each group were pooled (Figure 1), which resulted in the use of three APS plates to screen nine samples per group. The entire process, beginning with the addition of $50 \mu$ l of pooled diluted plasma to the measurement of the optical densities after quenching the reaction lasted approximately $4 \mathrm{~h}$. 
Table I. Autoantibodies elevated in the plasma of patients with breast cancer (test group) compared to donors with no history of breast cancer (reference group).

\begin{tabular}{|c|c|c|c|c|c|c|}
\hline \multirow[t]{2}{*}{ Target protein } & \multicolumn{2}{|c|}{ Mean concentration $(\mu \mathrm{g} / \mathrm{ml})$} & \multirow[t]{2}{*}{$p$-Value } & \multirow[t]{2}{*}{ Ratio (T/R) } & \multicolumn{2}{|c|}{ Trend in cancer ${ }^{+}$} \\
\hline & Test $(\mathrm{T}) \pm \mathrm{SD}$ & Reference $(\mathrm{R}) \pm \mathrm{SD}$ & & & $\begin{array}{c}\text { Breast } \\
\text { (present study) }\end{array}$ & Ovarian $(8)$ \\
\hline Interleukin-29 & $794.65 \pm 97.48$ & $225.80 \pm 33.33$ & $0.00001 *$ & 3.52 & Higher & Higher \\
\hline Survivin & $575.40 \pm 131.04$ & $384.37 \pm 162.35$ & $0.01498 *$ & 1.50 & Higher & Lower \\
\hline Growth hormone & $743.17 \pm 393.34$ & $387.13 \pm 208.10$ & $0.03350 *$ & 1.92 & Higher & Lower \\
\hline Osteoprotegerin & $1506.30 \pm 310.77$ & $890.85 \pm 321.41$ & $0.00702 *$ & 1.69 & Higher & Higher \\
\hline Resistin & $694.90 \pm 226.47$ & $397.00 \pm 102.26$ & $0.02185^{*}$ & 1.75 & Higher & Lower \\
\hline Cytotoxic T-lymphocyte associated antigen- 4 & $1170.60 \pm 483.34$ & $918.50 \pm 464.91$ & 0.37863 & 1.27 & Higher & Lower \\
\hline
\end{tabular}

*Statistically significantly different. T/R ratio: $\geq 1.30$ indicates higher level and $\leq 0.70$ indicates lower level in the test group compared to the reference group. ${ }^{+}$Compared to the reference (no cancer) group.

Levels of autoantibodies in plasma of test and reference groups. The OD readings obtained were evaluated by a cutoff that was determined by multiplying the mean OD by a factor of 1.5. Using this cut-off, a total of six autoantibodies (20\%) were identified as being elevated in the test or reference samples. Amongst these elevated autoantibodies, interleukin-29 (IL29), survivin (SUR), growth hormone (GRH), osteoprotegerin (OPG), and resistin (RES) were elevated in the test compared to the reference group $(p<0.05$; Table I). Although the level of autoantibody against cytotoxic T-lymphocyte associated antigen-4 (CTLA4) was higher in the test group (Table I), the difference in its levels between the two groups was not statistically significant.

\section{Discussion}

Autoantibodies continue to attract interest as potential circulating biomarkers for early detection and accurate diagnosis of disease. The ability to determine the presence/ absence and precise level of clinically-relevant autoantibodies in body fluids is important because it could determine the prognosis and treatment course. Thus, any easy and inexpensive method that can be used to screen, and can detect disease-relevant autoantibodies could help with diagnosis, prognostication and treatment of many diseases, including cancer. In this study, we demonstrated that a microtiter plate-based array system can be used to screen plasma for the presence of known autoantibodies. We observed that the autoantibody against IL29, occurred at a higher level in the test group compared to the reference group ( $p<0.001$; Table I). IL29, also known as interferon (IFN) lambda-1, is encoded by the gene IFNL1 located on chromosome 19 (21). IL29 is a type III interferon recently discovered and identified as a class II cytokine receptor ligand distantly related to members of the IL10 and type I
IFN families. Interferons comprise a large family of proteins that range in biological properties including cell growth inhibition, T-cell and natural killer cell cytotoxicity activation, T-helper type I response promotion and angiogenesis inhibition (22-24). IL29 has been observed to induce not only tumor-promoting effects, but also tumorinhibiting effects, depending on the type of cancer cells affected. In most types of cancer, IL29 typically has antitumor effects, but in multiple myeloma B, IL29 produces tumor-promoting effects. Thus, more research is needed to investigate and elucidate the relationship of IL29 with cancer (25). It is interesting to see that the levels of IL29 autoantibodies in the present breast cancer study, as well as the previous ovarian cancer study (8) were elevated in the test groups compared to the reference groups (Table I).

Autoantibody against survivin, also known as baculoviral inhibitor of apoptosis repeat-containing protein 5 (26), was elevated in the test samples compared to the reference samples $(p<0.02$; Table I). Survivin is encoded by BIRC5 gene located on chromosome 17 (26). Survivin is the smallest inhibitor of apoptosis protein and is strongly expressed in fetal tissues. It is undetectable in most normal adult tissues with the exception of the spleen, bone marrow, thymus, breast, intestinal crypt epithelial cells, and placenta $(27,28)$. Survivin transcript is markedly differentially expressed in various human cancer types (27), including that of the breast (28-33). The expression of survivin is regulated by both transcriptional and post-transcriptional mechanisms. Functional roles of this protein include being a regulator of cell division (34), a modulator of both apoptotic and nonapoptotic cell death, as well as a stress response factor to ensure continued cell proliferation and survival when faced with adverse environments (35). Additionally, survivin is known to antagonize angiogenesis (36) and act as a factor in resistance to a variety of anticancer therapies (37). 
Interestingly, high survivin expression is reported in ovarian carcinomas and this has been observed to be associated with higher clinical stage, lymph node metastasis, poorer differentiation grade, and therefore may potentially serve as a prognostic marker for patients with ovarian cancer because the levels of survivin were highest in ovarian carcinomas and lowest in benign ovarian masses (38). Cohen et al. obtained similar results indicating that the majority of ovarian carcinoma cases had elevated survivin expression which was associated with poor prognostic parameters (39). Notably, in our previous study (8), the level of autoantibody against survivin was found to be lower in patients with ovarian cancer compared to the reference group. If further studies reproduce this pattern, then the difference in levels of survivin autoantibodies in patients with breast and ovarian cancer could be clinically significant and useful.

GRH autoantibody level was elevated in plasma of the breast cancer group compared to donors without breast cancer $(p<0.04$; Table I). The major role of growth hormone is to stimulate the liver and other tissues to secrete insulinlike growth factor-1 (IGF1). GRH also stimulates the differentiation as well as proliferation of myoblasts, and amino acid uptake and protein synthesis in various tissues. It is encoded by the $G H 1$ gene located on chromosome 17 (40) and is a member of the somatotropin/prolactin family of hormones (41). Literature implicates growth hormonemediated signal transduction in the development and progression of a broad assortment of malignancies, including breast cancer (42). When GRH binds to its receptor, signal transduction pathways critical for cell growth and survival are activated $(43,44)$. Up-regulation of components involved in the pathways have been observed in various malignancies (42). Several studies describe the role that human growth hormone plays in human mammary gland neoplasia (45-47). This includes an altered risk of cancer that is related to gene polymorphisms within the GRH-IGF1 axis $(48,49)$, an increase in GRH expression in human mammary proliferative disorders (50), and an altered risk of breast cancer in the pathological conditions resulting from irregular GRH levels $(51,52)$. Human GRH binding protein forms complexes with GRH in serum, and an increase in this has been associated with a 3 -fold increased risk of breast cancer (53). Correlations have been made between human GRH expression with various cancer types, and several sporadic cases of ectopic GRH secretion associated with malignancy have been documented, including in ovarian cancer (54). Notably, our previous study with plasma from patients with ovarian cancer showed that GRH autoantibody levels were not elevated in ovarian cancer (8).

It was interesting to find that the autoantibody against OPG was elevated in the breast cancer group $(p<0.01$; Table I) because it was also significantly higher $(p<0.001)$ in the ovarian cancer group compared to the reference group (8).
OPG, also known as tumor necrosis factor receptor superfamily member $11 \mathrm{~B}$, is encoded by the gene TNFRSF $11 B$ located on chromosome 8 (55). It is a secreted protein with no cytoplasmic domain or transmembrane (56, 57 ) and it is a negative regulator of bone turnover (58). It is expressed in other tissues such as the skin, heart, stomach, lung, kidney, liver, intestines, and breast $(59,60)$. Recent data shows OPG production in breast tumor cells and its ability to promote both tumor growth and metastasis (61, 62). In vitro studies propose that acting as a decoy receptor, OPG binds to tumor necrosis factor (TNF-related apoptosisinducing ligand (TRAIL), thus inhibiting apoptosis of cancer cells $(63,64)$. Numerous evidence exists that suggests an association between OPG and malignancy (65). OPG plays a range of functional roles in cancer cell survival and progression, including tumor cell survival $(56,65)$, TRAILinduced apoptosis resistance (66), cell phenotype, proliferation, and angiogenesis (67). Results from a study performed by Goswami and Sharma-Waila showed a consistently high OPG expression in infiltrating ductal carcinoma breast tissue samples when compared to control, uninvolved tissue samples (62). Moreover, when these results are taken together with other observations, it is proposed that OPG plays a major role in the angiogenic signature of aggressive breast tumor microenvironments (62). A study performed by Lane et al. showed that OPG acts as a survival factor by protecting TRAIL-induced apoptosis of ovarian cancer cells (68). These reports indicate the potential role of OPG in both development and progression of ovarian cancer, and the study by Jiang $e t$ al. suggests that a set of five serum markers, including OPG can be used for the detection of ovarian cancer (69). Our previous results of autoantibody profiling in ovarian cancer (8) and the current profiling of plasma samples from patients with breast cancer demonstrate elevated levels of OPG autoantibodies in the cancer groups. This suggest that the level of autoantibodies against OPG could have clinical significance and utility in breast and ovarian cancer.

The level of autoantibody against the hormone RES was higher in breast cancer group compared to the group without cancer $(p<0.03$; Table I). The role of RES appears to be the suppression of the ability of insulin to stimulate glucose uptake by adipose cells (70). It is a unique signaling molecule encoded by the RETN gene, located on chromosome 19 (71) and is secreted by adipocytes (72). It is believed that there is an association between the level of RES and the risk of developing breast cancer, and this association is independent of serum glucose, body mass index, adiponectin, age, and status of menopause (73). Dalamaga et al. observed that the mean serum level of RES was significantly higher in postmenopausal breast cancer cases than in healthy controls and patients with benign breast lesions. They found that RES was significantly positively associated with tumor and 
inflammatory markers, tumor grade and lymph node invasion, tumor size, and cancer stage. Moreover, the authors found a correlation between RES and some well-known tumor markers (carcinoma antigen 15-3 and carcinoembryonic antigen) as well as inflammatory markers (C-reactive protein, interleukin 6 and tissue necrotic factor alpha) (74), which are known to be associated with poor prognosis in breast cancer (75-77). It is believed that although diagnostic performance of RES was low in regard to differentiating patients with breast cancer from those with benign breast lesions and healthy controls, RES may have the potential to be a good biomarker for breast cancer, reflecting inflammatory states and advanced disease stage (74). It was found that the serum levels of adiponectin, RES, and plasminogen activator inhibitor are not significantly different between women with ovarian carcinoma, borderline or benign tumor (78). Conflicting results have been reported with regards to the diagnostic value of circulating adipokines in ovarian cancer (79-81). Our previous study showed that resistin autoantibody levels are lower in the test group versus the reference group (Table I) (8).

Elevated levels of the autoantibody against CTLA4 were detected in the plasma of both breast cancer and reference groups. Although the level in the breast cancer group was higher than that in the reference group, the difference was not statistically significant ( $p>0.3$; Table I). CTLA4, which is encoded by the CTLA4 gene located on chromosome 2 (82), is an immune checkpoint molecule (83). A significant barrier to antitumor therapies is tumor-derived immune dysregulation via immune checkpoints which are utilized by cancer cells to avoid attacks from the immune system (83). The immune checkpoint molecules that can block antitumor immunity comprise the immunosuppressive microenvironment consequential of cancer cells $(84,85)$. CTLA4 is an inhibitory receptor which acts to turn-off T-cell-targeting tumor antigens (86). It has been reported that a high CTLA4 level correlates with poor survival of patients with melanoma, renal cell carcinoma and colorectal cancer (87-89), and a significantly higher level was present in patients with breast cancer (90). Interestingly, a lower level of CTLA4 was associated with poorer survival in patients with ovarian cancer (91). Notably, our previous study showed that levels of autoantibodies against CTLA4 were lower in the plasma of patients with ovarian cancer (Table I) (8).

In conclusion, the APS detected six autoantibodies that occurred at higher levels in human plasma samples according to the criteria we used in this study. Amongst them, five autoantibodies were present at significantly different levels in the test (breast cancer) group compared to the reference (no cancer) group. The finding that the same autoantibodies are detected in cancer and reference groups indicates that not all the autoantibodies detected in plasma may be relevant or important in disease diagnosis and classification. Thus, having a method that permits the detection and precise quantitation of autoantibody levels in clinical samples will be necessary, and will help in deciphering which autoantibody could be used for early disease detection, disease classification, prognostication or monitoring of the progress of treatment. No far-reaching conclusion can be drawn concerning the potential clinical usefulness of the identified autoantibodies because of the very small sample size. Nevertheless, this study further demonstrates that a simple and inexpensive microtiter-based array system can be used to detect and quantify multiple autoantibodies in plasma. This could provide a fast and simple method for screening of clinical samples to determine the presence/ absence of known and clinically relevant autoantibodies.

\section{Conflicts of Interest}

The Authors declare that the autoantibody profiling system used in the study is manufactured by ITSI-Biosciences, a for-profit business owned by one of the authors (RIS). This ownership interest did not in any way affect the conduct of the experiment nor the results obtained.

\section{Acknowledgements}

The human plasma samples used for the study were obtained from the Windber Research Institute Tissue Repository, Windber PA, USA.

\section{References}

1 Siegel RL, Miller KD and Jemal A: Cancer Statistics, 2017. CA Cancer J Clin 67: 7-30, 2017.

2 SEER Cancer Stat Facts: Female Breast Cancer. National Cancer Institute. Bethesda, MD, http://seer.cancer.gov/statfacts/html/ breast.html

3 Bleyer A and Welch HG: Effect of three decades of screening mammography on breast-cancer incidence. New Engl J Med 367: 1998-2005, 2012.

4 Weigelt B, Geyer FC and Reis-Filho JS: Histological types of breast cancer: How special are they? Mol Oncol 4: 192-208, 2010.

5 Desmetz C, Mange A, Maudelonde $\mathrm{T}$ and Solassol J: Autoantibody signatures: progress and perspectives for early cancer detection. J Cell Mol Med 15: 2013-2024, 2011.

$6 \mathrm{Lu} \mathrm{H}$ and Goodell V: Humoral immunity directed against tumorassociated antigens as potential biomarkers for the early diagnosis of cancer. J Proteome Res 45: 88-94, 2008.

7 Anderson KS, Cramer DW, Sibani S, Walstrom G, Wong J, Park J, Qiu J, Vitonis A and LaBaer, J: Autoantibody signature for the serologic detection of ovarian cancer. J Proteome Res 14: 578$586,2015$.

8 Somiari RI, Sutphen R, Renganathan K, Russell S, Pastwa E and Somiari SA: A low-density antigen array for detection of disease-associated autoantibodies in human plasma. Cancer Genom Proteom 13: 13-19, 2016. 
9 Madi A, Hecht I, Bransburg-Zabary S, Merbl Y, Pick A, ZuckerToledano M, Quintana FJ, Tauber AI, Cohen IR and Ben-Jacob, E: Organization of the autoantibody repertoire in healthy newborns and adults revealed by system level informatics of antigen microarray data. Proc Natl Acad Sci USA 106: 1448414489, 2009.

10 Elkon K and Casali P: Nature and functions of autoantibodies. Nat Clin Pract Rheum 4: 491-498, 2008.

11 Plotz PH: The autoantibody repertoire: searching for order. Nat Rev Immunol 3: 73-78, 2003.

12 Hanash SM, Baik CS and Kallioniemi O: Emerging molecular biomarkers-blood-based strategies to detect and monitor cancer. Nat Rev Clin Oncol 8: 142-150, 2011.

13 Anderson KS and LaBaer J: The sentinel within: Exploiting the immune system for cancer biomarkers. J Proteome Res 4: 11231133, 2005.

14 Mange A, Lacombe J, Bascoul-Mollevi C, Jarlier M, Lamy PJ, Rouanet P, Maudelonde T and Solassol J: Serum autoantibody signature of ductal carcinoma in situ progression to invasive breast cancer. Clin Cancer Res 18: 1992-2000, 2012.

15 Wang XJ, Yu JJ, Sreekumar A, Varambally S, Shen R, Giacherio D, Mehra R, Montie JE, Pienta KJ, Sanda MG, Kantoff PW, Rubin MA, Wei JT, Ghosh D and Chinnaiyan AM: Autoantibody signatures in prostate cancer. New Engl J Med 353: 1224-1235, 2005

16 Qiu J, Choi G, Li L, Wang H, Pitteri SJ, Pereira-Faca SR, Krasnoselsky AL, Randolph TW, Omenn GS, Edelstein C and Barnett MJ: Occurrence of autoantibodies to annexin I, 14-3-3 theta and LAMR1 in prediagnostic lung cancer sera. J Clin Oncol 26: 5060-5066, 2008

17 Zhong L, Coe SP, Stromberg AJ, Khattar NH, Jett JR and Hirschowitz EA: Profiling tumor-associated antibodies for early detection of non-small cell lung cancer. J Thorac Oncol 1: 513519, 2006.

18 Caron M, Choquet-Kastylevsky G and Joubert-Caron R: Cancer immunomics: using autoantibody signatures for biomarker discovery. Mol Cell Proteomics 6: 1115-1122, 2007.

19 Chapman CJ, Thorpe AJ, Murray A, Parsy-Kowalska C, Allen J, Stafford K, Chauhan A, Kite T, Maddison P and Robertson J: Immuno-biomarkers in small cell lung cancer: potential early cancer signals. Clin Cancer Res 17: 1474-1480, 2011.

20 MyAssays Ltd: Four Parameter Logistic Curve Online Data Analysis Tool. 2017, http://www.myassays.com/four-parameterlogistic-curve.assay

21 UniProt: UniProtKB - Q8IU54 (IFNL1_HUMAN). 2017, http://www.uniprot.org/uniprot/Q8IU54

22 Leaman DW: Mechanism of interferon action. Prog Mol Subcell Biol 20: 101-142, 1998.

23 Pfeffer LM, Dinarello CA, Herberman RB, Williams BR, Borden EC, Bordens R, Walter MR, Nagabhushan TL, Trotta PP and Pestka S: Biological properties of recombinant $\alpha$ interferons: 40th anniversary of the discovery of interferons. Cancer Res 58: 2489-2499, 1998.

24 Naumnik W, Naumnik B, Niewiarowska K, Ossolinska M and Chyczewska E: Novel cytokines: IL-27, IL-29, IL-31 and IL-33. Can they be useful in clinical practice at the time diagnosis of lung cancer? Exp Oncol 34: 348-353, 2012.

25 Kelm NE, Zhu Z, Ding VA, Xiao H, Wakefield MR, Bai Q and Fang Y: The role of IL-29 in immunity and cancer. Crit Rev Oncol Hemat 106: 91-98, 2016.
26 NCBI: BIRC5 baculoviral IAP repeat containing 5 [Homo sapiens (human)]. 2017, https://www.ncbi.nlm.nih.gov/gene/332

27 Li F: Survivin study: what is the next wave? J Cell Physiol 197: 8-29, 2003.

28 Végran F, Boidot R, Oudin C, Riedinger JM and Lizard-Nacol S: Distinct expression of BIRC5 splice variants in breast carcinomas. Int J Oncol 27: 1151-1157, 2005.

29 Nasu S, Yagihashi A, Izawa A, Saito K, Asanuma K, Nakamura M, Kobayashi D, Okazaki M and Watanabe N: Survivin mRNA expression in patients with breast cancer. Anticancer Res 3: 1839-1843, 2002.

30 O'Driscoll L, Linehan R and Clynes M: Survivin: role in normal and in pathological conditions. Curr Cancer Drug Tar 2: 131152, 2003.

31 Ryan B, O'Donovan N, Browne B, O'Shea C, Crown J, Hill AD, McDermott E, O'Higgins $\mathrm{N}$ and Duffy MJ: Expression of survivin and its splice variants survivin- $2 \mathrm{~B}$ and survivin- $\Delta \mathrm{Ex} 3$ in breast cancer. Br J Cancer 92: 120-124, 2005.

32 Végran F, Boidot R, Oudin C, Defrain C, Rebucci M and LizardNacol S: Association of $p 53$ gene alterations with the expression of antiapoptotic survivin splice variants in breast cancer. Oncogene 26: 290-297, 2007.

33 Boidot R, Végran F and Lizard-Nacol S: Predictive value of survivin alternative transcript expression in locally advanced breast cancer patients treated with neoadjuvant chemotherapy. Int J Mol Med 23: 285-291, 2009.

34 Connell CM, Wheatley SP and McNeish IA: Nuclear survivin abrogates multiple cell cycle checkpoints and enhances viral oncolysis. Cancer Res 68: 7923-7931, 2008.

35 Altieri DC: T-Cell expansion: the survivin interface between cell proliferation and cell death. Immunity 22: 534-535, 2005.

36 Obexer P, Hagenbuchner J, Unterkircher T, Sachsenmaier N, Seifarth C, Böck G, Porto V, Geiger K and Ausserlechner M: Repression of BIRC5/survivin by FOXO3/FKHRL1 sensitizes human neuroblastoma cells to DNA damage-induced apoptosis. Mol Biol Cell 20: 2041-2048, 2009.

$37 \mathrm{Wu}$ YH, You Y, Chen ZC and Zou P: Reversal of drug resistance by silencing survivin gene expression in acute myeloid leukemia cells. Acta Biochim Pol 55: 673-680, 2008.

38 Liguang Z, Peishu L, Hongluan M, Hong J, Rong W, Wachtel MS and Frezza EE: Survivin expression in ovarian cancer. Exp Oncol 29: 121-125, 2007.

39 Cohen C, Lohmann CM, Cotsonis G, Lawson D and Santoianni R: Survivin expression in ovarian carcinoma: correlation with apoptotic markers and prognosis. Modern Pathol 16: 574-583, 2003.

40 Uniprot: UniProtKB - P01241 (SOMA_HUMAN). 2017, http://www.uniprot.org/uniprot/P01241

41 NCBI: GH1 growth hormone 1 [Homo sapiens (human)]. 2017, https://www.ncbi.nlm.nih.gov/gene/2688

42 Perry JK, Mohankumar KM, Emerald BS, Mertani HC and Lobie PE: The contribution of growth hormone to mammary neoplasia. J Mammary Gland Biol 13: 131-145, 2009.

43 Le Roith D, Bondy C, Yakar S, Liu JL and Butler A: The somatomedin hypothesis: 2001. Endocr Rev 22: 53-74, 2001.

44 Zhu T, Goh EL, Graichen R, Ling L and Lobie PE: Signal transduction via the growth hormone receptor. Cell Signal 13: 599-616, 2001.

45 Laban C, Bustin SA and Jenkins PJ: The GHIGFI axis and breast cancer. Trends Endocrin Met 14: 28-34, 2003. 
46 Perry JK, Emerald BS, Mertani HC and Lobie PE: The oncogenic potential of growth hormone. Growth Horm IGF Res 16: 277-289, 2006.

47 Waters MJ and Barclay JL: Does growth hormone drive breast and other cancers? Endocrinology 148: 4533-4535, 2007.

48 Le Marchand L, Donlon T, Seifried A, Kaaks R, Rinaldi S and Wilkens LR: Association of a common polymorphism in the human $G H 1$ gene with colorectal neoplasia. J Natl Cancer I 94: 454-460, 2002.

49 Wagner $\mathrm{K}$, Hemminki $\mathrm{K}$ and Forsti A: The GH1/IGF1 axis polymorphisms and their impact on breast cancer development. Breast Cancer Res Treat 104: 233-248, 2007.

50 Raccurt M, Lobie PE, Moudilou E, Garcia-Caballero T, Frappart L, Morel G and Mertani HC: High stromal and epithelial human $\mathrm{GH}$ gene expression is associated with proliferative disorders of the mammary gland. J Endocrinol 175: 307-318, 2002.

51 Jenkins PJ: Acromegaly and cancer. Horm Res 62(Suppl 1): 108$115,2004$.

52 Shevah O and Laron Z: Patients with congenital deficiency of IGFI seem protected from the development of malignancies: a preliminary report. Growth Horm IGF Res 17: 54-57, 2007.

53 Pazaitou-Panayiotou K, Kelesidis T, Kelesidis I, Kaprara A, Blakeman J, Vainas I, Mpousoulegas A, Williams CJ and Mantzoros C: Growth hormone-binding protein is directly and IGFBP-3 is inversely associated with risk of female breast cancer. Eur J Endocrinol 156: 187-194, 2007.

54 Kaganowicz A, Farkouh NH, Frantz AG and Blaustein AU: Ectopic human growth hormone in ovaries and breast cancer. J Clin Endocr Metab 48: 5-8, 1979.

55 NCBI: TNFRSF11B TNF receptor superfamily member $11 \mathrm{~b}$ [Homo sapiens (human)]. 2017, https://www.ncbi.nlm.nih.gov/ gene/4982

56 Holen I and Shipman CM: Role of osteoprotegerin (OPG) in cancer. Clin Sci 110: 279-91, 2006.

57 Nelson CA, Warren JT, Wang MW, Teitelbaum SL and Fremont DH: RANKL employs distinct binding modes to engage RANK and the osteoprotegerin decoy receptor. Structure 20: 1971-82, 2012.

58 Boyle WJ, Simonet WS and Lacey DL: Osteoclast differentiation and activation. Nature 423: 337-42, 2003.

59 Thomas RJ, Guise TA, Yin JJ, Elliott J, Horwood NJ, Martin TJ and Gillespie MT: Breast cancer cells interact with osteoblasts to support osteoclast formation. Endocrinology 140: 4451-4458, 1999.

60 Chikatsu N, Takeuchi Y, Tamura Y, Fukumoto S, Yano K, Tsuda E, Ogata E and Fujita T: Interactions between cancer and bone marrow cells induce osteoclast differentiation factor expression and osteoclast-like cell formation in vitro. Biochem Bioph Res Co 267: 632-637, 2000.

61 Weichhaus M, Chung ST and Connelly L: Osteoprotegerin in breast cancer: beyond bone remodeling. Mol Cancer 14: 117, 2015.

62 Goswami S and Sharma-Walia N: Osteoprotegerin secreted by inflammatory and invasive breast cancer cells induces aneuploidy, cell proliferation and angiogenesis. BMC Cancer 15: 935, 2015

63 Rahman M, Pumphrey JG and Lipkowitz S: The TRAIL to targeted therapy of breast cancer. Adv Cancer Res 103: 43-73, 2009.

64 Farooqi AA, Fayyaz S, Tahir M, Iqbal MJ and Bhatti S: Breast cancer proteome takes more than two to tango on TRAIL: beat them at their own game. J Membrane Biol 245: 763-777, 2012.
65 Holen I, Cross SS, Neville-Webbe HL, Cross NA, Balasubramanian SP, Croucher PI, Evans CA, Lippitt JM, Coleman $\mathrm{RE}$ and Eaton CL: Osteoprotegerin (OPG) expression by breast cancer cells in vitro and breast tumours in vivo - a role in tumour cell survival? Breast Cancer Res Tr 92: 207-215, 2005.

66 De Toni EN, Thieme SE, Herbst A, Behrens A, Stieber P, Jung A, Blum H, Göke B and Kolligs FT: OPG is regulated by $\beta$ catenin and mediates resistance to TRAIL-induced apoptosis in colon cancer. Clin Cancer Res 14: 4713-4718, 2008.

67 Cross SS, Yang Z, Brown NJ, Balasubramanian SP, Evans CA, Woodward JK, Neville-Webbe HL, Lippitt JM, Reed MW, Coleman RE and Holen I: Osteoprotegerin (OPG) - A potential new role in the regulation of endothelialcell phenotype and tumour angiogenesis? Int J Cancer 118: 1901-1908, 2006.

68 Lane D, Matte I, Rancourt C and Piché A: Osteoprotegerin (OPG) protects ovarian cancer cells from TRAIL-induced apoptosis but does not contribute to malignant ascites-mediated attenuation of TRAIL-induced apoptosis. J Ovarian Res 5: 34, 2012.

69 Jiang W, Huang R, Duan C, Fu L, Xi Y, Yang Y, Yang WM, Yang D, Yang DH and Huang RP: Identification of five serum protein markers for detection of ovarian cancer by antibody arrays. PloS One 8: e76795, 2013.

70 Chumakov AM, Kubota $\mathrm{T}$ and Walter S, Koeffler HP: Identification of murine and human XCP1 genes as C/EBP- $\varepsilon$ dependent members of FIZZ/Resistin gene family. Oncogene 23: 3414-3425, 2004.

71 NCBI: RETN resistin [Homo sapiens (human)]. 2017, https://www.ncbi.nlm.nih.gov/gene/56729

72 Steppan CM, Bailey ST, Bhat S, Brown EJ, Banerjee RR, Wright CM, Patel HR, Ahima RS and Lazar MA: The hormone resistin links obesity to diabetes. Nature 409: 307-312, 2001.

73 Kang JH, Yu BY and Youn DS: Relationship of serum adiponectin and resistin levels with breast cancer risk. J Korean Med Sci 22: 117-121, 2007.

74 Dalamaga M, Sotiropoulos G, Karmaniolas K, Pelekanos N, Papadavid E and Lekka A: Serum resistin: a biomarker of breast cancer in postmenopausal women? Association with clinicopathological characteristics, tumor markers, inflammatory and metabolic parameters. Clin Biochem 46: 584-590, 2013.

75 Duffy MJ, Evoy D and McDermott EW: CA 15-3: uses and limitation as a biomarker for breast cancer. Clinica Chim Acta 411: 1869-1874, 2010.

76 Papadopoulou E, Tripsianis G, Anagnostopoulos K, Tentes I, Kakolyris S, Galazios G, Sivridis E, Simopoulos K and Kortsaris A: Significance of serum tumor necrosis factor-alpha and its combination with $H E R 2$ codon 655 polymorphism in the diagnosis and prognosis of breast cancer. Int J Biol Marker 25: 126-135, 2009.

77 Ravishankaran P and Karunanithi R: Clinical significance of preoperative serum interleukin-6 and C-reactive protein level in breast cancer patients. World J Surg Oncol 9: 18, 2011.

78 Aune G, Stunes AK, Lian AM, Reseland JE, Tingulstad S, Torp $\mathrm{SH}$ and Syversen U: Circulating interleukin-8 and plasminogen activator inhibitor-1 are increased in women with ovarian carcinoma. Results Immunol 2: 190-195, 2012.

79 Serin IS, Tanriverdi F, Yilmaz MO, Ozcelik B and Unluhizarci $\mathrm{K}$ : Serum insulin-like growth factor (IGF)-I, IGF-binding protein (IGFBP)-3, leptin concentrations and insulin resistance in benign and malignant epithelial ovarian tumors in postmenopausal women. Gynecol Endocrinol 24: 117-121, 2008. 
80 Visintin I, Feng Z, Longton G, Ward DC, Alvero AB, Lai Y, Tenthorey J, Leiser A, Flores-Saaib R, Yu H and Azori M: Diagnostic markers for early detection of ovarian cancer. Clin Cancer Res 14: 1065-1072, 2008

81 Vrzalova J, Prazakova M, Novotny Z, Topolcan O, Casova M and Holubec L: Test of ovarian cancer multiplex xMAP technology panel. Anticancer Res 29: 573-576, 2009.

82 UniProt: UniProt KB - P16410 (CTLA4_HUMAN). 2017, http://www.uniprot.org/uniprot/P16410

83 Mellman I, Coukos G and Dranoff G: Cancer immunotherapy comes of age. Nature 480: 480-489, 2011.

84 Koch MA, Thomas KR, Perdue NR, Smigiel KS, Srivastava S and Campbell DJ: T-bet+ Treg cells undergo abortive Th1 cell differentiation due to impaired expression of IL-12 receptor $\beta 2$. Immunity 37: 501-510, 2012.

$85 \mathrm{Yu}$ HM, Yang JL, Jiao SC, Wang JD and Li Y: TGF- $\beta 1$ precursor and CD8 are potential prognostic and predictive markers in operated breast cancer. J Huazhong Univ Sci-Med 34: 51-58, 2014.

86 Pardoll DM: The blockade of immune checkpoints in cancer immunotherapy. Nat Rev Cancer 12: 252-264, 2012.

87 Topalian SL, Hodi FS, Brahmer JR, Gettinger SN, Smith DC, McDermott DF, Powderly JD, Carvajal RD, Sosman JA, Atkins MB and Leming PD: Safety, activity, and immune correlates of anti-PD-1 antibody in cancer. N Engl J Med 366: 2443-2454, 2012.
88 Gunturi A and McDermott DF: Potential of new therapies like anti-PD1 in kidney cancer. Curr Treat Option Oncol 15: 137146, 2014.

89 Brahmer JR, Tykodi SS, Chow LQ, Hwu WJ, Topalian SL, Hwu P, Drake CG, Camacho LH, Kauh J, Odunsi K and Pitot HC: Safety and activity of anti-PD-L1 antibody in patients with advanced cancer. N Engl J Med 366: 2455-2465, 2012.

90 Erfani N, Razmkhah M and Ghaderi A: Circulating soluble CTLA4 (sCTLA4) is elevated in patients with breast cancer. Cancer Invest 28: 828-832, 2010.

91 Zhu C, Ma X, Ling W, Xiao Y and Győrffy B: Prognostic value of PDCD-1 and CTLA-4 in ovarian cancer patients. Int J Clin Exp Med 9: 21952-21960, 2016.
Received August 12, 2017

Revised September 20, 2017

Accepted September 22, 2017 